\title{
Phylogenetic analysis of Myriapoda using three nuclear protein-coding genes
}

\author{
Jerome C. Regier, ${ }^{\mathrm{a}, *}$, Heather M. Wilson ${ }^{\mathrm{b}, 1}$, Jeffrey W. Shultz ${ }^{\mathrm{b}, *}$ \\ ${ }^{a}$ Center for Biosystems Research, University of Maryland Biotechnology Institute, 5140 Plant Sciences Building, College Park, \\ MD 20742-4450, United States \\ ${ }^{\mathrm{b}}$ Department of Entomology, University of Maryland, Plant Sciences Building, College Park, MD 20742, United States
}

Received 14 April 2004; revised 18 June 2004

Available online 5 November 2004

\begin{abstract}
We assessed the ability of three nuclear protein-encoding genes - elongation factor-1 $\alpha$ (EF-1 $\alpha)$, RNA polymerase II (Pol II), and elongation factor-2 (EF-2) - from 59 myriapod and 12 non-myriapod species to resolve phylogenetic relationships among myriapod classes and orders. In a previous study using EF-1 $\alpha$ and Pol II (2134 nt combined) from 34 myriapod taxa, Regier and Shultz recovered widely accepted classes, orders, and families but failed to resolve interclass and interordinal relationships. The result was attributed to heterogenous rates of cladogenesis (specifically, the inability of the slowly evolving sequences to capture phylogenetic signal during rapid phylogenetic diversification) but the possibility of inadequate taxon sampling or limited sequence information could not be excluded. In the present study, the myriapod taxon sample was increased by 25 taxa (73\%) and sequence length per taxon was effectively doubled through addition of EF-2 (4318 nt combined). Parsimony and Bayesian analyses of the expanded data set recovered a monophyletic Myriapoda, all four myriapod classes and all multiply sampled orders, often with high node support. However, except for three diplopod clades (Colobognatha, Helminothomorpha, and a subgroup of Pentazonia), few interordinal relationships and no interclass relationships were well supported. These results are similar to those of the earlier study by Regier and Shultz, which indicates that taxon sample and sequence length alone do not readily explain the weakly supported resolution in the earlier study. We review recent paleontological evidence to further develop our proposal that heterogeneity in phylogenetic signal provided by our slowly evolving sequences is due to heterogeneity in the temporal structure of myriapod diversification.
\end{abstract}

(C) 2004 Elsevier Inc. All rights reserved.

Keywords: Myriapoda; Diplopoda; Chilopoda; Arthropoda; Phylogeny; Elongation factor-1 $\alpha$; Elongation factor-2; RNA polymerase II

\section{Introduction}

Phylogenetic relationships among the myriapod classes (Dohle, 1988; Edgecombe and Giribet, 2002; Hilken and Kraus, 1994; Koch, 2003; Kraus, 1998, 2001; Regier and Shultz, 2001a) are controversial, as are relationships

\footnotetext{
${ }^{*}$ Corresponding authors. Fax: +1 3013149075.

E-mail addresses: regier@umd.edu (J.C. Regier), jshultz@umd.edu (J.W. Shultz)

${ }^{1}$ Present address: Department of Geology and Geophysics, Yale University, USA.
}

among orders within the most diverse of these, Diplopoda (Enghoff, 1984; Enghoff et al., 1993; Sierwald et al., 2003). Regier and Shultz (2001a) conducted a moleculebased phylogenetic analysis to resolve higher relationships within Myriapoda. The analysis included 15 outgroup species drawn from Pancrustacea and Chelicerata and 34 species representing all myriapod classes except Pauropoda, all chilopod orders, and 10 of the 15 extant diplopod orders. Sequences from two conserved nuclear protein-coding genes, elongation factor-1 $\alpha$ (1092 nt, $364 \mathrm{aa})$ and RNA polymerase II ( 1042 nt, $346 \mathrm{aa})$, were obtained from each representative, and the data 
were analyzed using parsimony- and likelihood-based methods. The analyses reconstructed Myriapoda and all multiply sampled myriapod classes and orders but failed to provide compelling support for relationships among classes or orders. Although the analysis was based on a large matrix, inadequate taxon sampling or sequence information could still be invoked to explain poor phylogenetic resolution of this large, diverse group of arthropods. However, Regier and Shultz (2001a) presented evidence indicating that the evolutionary rate of their sequences should be appropriate and suggested instead that poor resolution was caused by heterogenous rates of cladogenesis; that is, rapid diversification of classes and orders may not have allowed sufficient time for phylogenetically informative changes to accumulate but that longer intervals between these radiations could have provided ample phylogenetic signal.

The present analysis was undertaken to address the "data and taxon insufficiency" and "rapid cladogenesis" explanations for the results of Regier and Shultz (2001a). Specifically, we have increased the taxon sample from 34 to 59 myriapod species so as to encompass representatives from all myriapod classes, 14 of the 15 diplopod orders, and greater representation of previously sampled groups. The outgroup taxa were the same. In addition, sequence data were essentially doubled through addition of a third nuclear protein-coding gene, elongation factor-2 (2184 nt, 728 aa). Lastly, we reviewed the fossil record of Myriapoda, especially Diplopoda, to assess its congruence with the "rapid cladogenesis" hypothesis.

Despite using a data matrix enhanced by additional taxa and sequence information, our analysis produced results that are remarkably similar to that reported by Regier and Shultz (2001a). Specifically, myriapod classes and orders tended to be recovered with strong to moderate support, but few relationships among classes or among orders were resolved. The fact that additional taxa and sequence information did not significantly increase the phylogenetic signal does not mean that adding even more taxa and/or sequence data will also fail to increase signal; nevertheless, these observations make more compelling the proposal that differential phylogenetic resolution is caused by heterogeneity in the timing of phylogenetic diversification (i.e., rapid radiations of classes and orders). Our review of the available paleontological information is also consistent with this conclusion.

\section{Materials and methods}

\subsection{Taxon sampling}

Fifty-nine myriapod species, multiply representing all four classes, were sampled for three genes each, elongation factor-1 $\alpha(E F-1 \alpha)$, largest subunit of RNA polymerase II (Pol II) and elongation factor-2 (EF-2).
Two distinct Pol II sequences were obtained from Lithobius forficatus, so two "taxa," Lfo_A and Lfo_B, were created with identical EF-1 $\alpha$ and EF-2 sequences but distinct Pol II sequences. Four diverse examplars of Pancrustacea and seven of Chelicerata were sampled as outgroups. Higher taxon names, species names and GenBank accession numbers are shown in Table 1. All phylogenetic analyses (described below) were based on these 71 taxa. Relationships among outgroup taxa match previous results (Regier and Shultz, 2001a) and are not shown. Voucher specimens will be deposited in the National Museum of Natural History (Smithsonian Institution).

\subsection{Specimen preservation and the data set}

Live specimens were collected into $100 \%$ ethanol at ambient temperature, held for brief periods (i.e., from hours to weeks) at room temperature, and then stored at $-85^{\circ} \mathrm{C}$. Total nucleic acids were extracted from wet tissue weighing a few milligrams using the SV Total RNA Isolation kit (Promega) with the DNase step omitted. The extracts were dissolved in water to a volume of $100 \mu \mathrm{l}$. Reverse transcription reactions used $0.1-1.0 \mu \mathrm{l}$ of this as template. Starting from specimen-extracted total nucleic acids, specific mRNA sequences (4,377 nt total) for EF-1 $\alpha$ (1131 nt excluding terminal PCR primer sequences), Pol II (1062 nt excluding the terminal PCR primer sequences), and EF-2 (2184 nt excluding terminal PCR primer sequences) were reverse transcribed and amplified by the polymerase chain reaction using previously described conditions and oligonucleotide primers (Regier and Shultz, 2001b and references therein; Regier et al., 2005). In all cases, nested PCR amplifications were performed.

PCR fragments were sequenced directly from the M13 sequences present at the $5^{\prime}$ ends of all PCR primers, using fluorescent-labeled dye terminators and an automated DNA sequencer (Regier and Shi, 2005). The PREGAP and GAP4 programs within the Staden package (Staden et al., 1999) were used to edit and assemble contigs. The Genetic Data Environment software package (version 2.2, Smith et al., 1994) was used to manually align assembled sequences and to construct nucleotide data matrices for phylogenetic analysis. The three-gene nucleotide sequence alignment with annotations can be downloaded as a text file from Supplementary material or from http://www.umbi.umd.edu/users/ jcrlab/Myriapoda3gn2004.doc. MacClade (Maddison and Maddison, 1992) was used to create amino acid matrices. This matrix was $96.9 \%$ complete, with the remainder represented by polymorphisms and Xs. For EF- $1 \alpha$ and Pol II, there were no indels across Myriapoda. For EF-2, there was a single informative indel region to which we assigned three possible states $(0,+3$, and +6) corresponding to the number of additional nucleotides at that site relative to the nematode 
Table 1

Taxon classification, sampling, and GenBank accession numbers ${ }^{\mathrm{a}}$

\begin{tabular}{|c|c|c|c|c|c|}
\hline \multirow[t]{2}{*}{ Higher classification } & \multirow[t]{2}{*}{ Taxon } & \multirow{2}{*}{$\begin{array}{l}\text { Lab } \\
\text { code }\end{array}$} & \multicolumn{3}{|c|}{ GenBank Accession No. } \\
\hline & & & EF-1 $\alpha$ & Pol II & $\mathrm{EF}-2$ \\
\hline \multicolumn{6}{|l|}{ Myriapoda } \\
\hline \multicolumn{6}{|l|}{ Diplopoda: } \\
\hline \multirow[t]{5}{*}{ Julida } & Cylindroiulus punctatus & $\mathrm{Cpu}$ & AF240792 & AF240904-AF240906 & AY310252 \\
\hline & Ophyiulus pilosus & Jul & AF240798 & AF240921-AF240923 & AY310264 \\
\hline & Proteroiulus fuscus & $\mathrm{Pfu}$ & AF063415 & $\begin{array}{l}\text { AF139000, AF240941, } \\
\text { AF240942 }\end{array}$ & AY310277 \\
\hline & Nemasoma varicorne & Nva & AF240800 & AF240928-AF240930 & AY310270, AY310271 \\
\hline & Uroblaniulus canadensis & Par2 & AF240803 & AF240936, AF240937 & AY310275 \\
\hline \multirow[t]{2}{*}{ Chordeumatida } & Cleidogona major & $\mathrm{Cle} 2$ & AF240791 & AF240901-AF240903 & AY310249, AY310250 \\
\hline & Striaria columbiana & Str2 & AF240811 & AF240961-AF240963 & AY310292 \\
\hline Callipodida & Abacion magnum & Ama2 & AF240788 & AF240893-AF240895 & AY305488 \\
\hline \multirow[t]{2}{*}{ Spirostreptida } & Orthoporus ornatus & Oor3 & AF240802 & AF240934, AF240935 & AY310273, AY310274 \\
\hline & Trachyiulus nordquisti & Tnor & AY305479 & AY305624-AY305626 & AY305525 \\
\hline \multirow[t]{2}{*}{ Polyzoniida } & Polyzonium germanicum & Pge & AF240805 & AF240943-AF240945 & AY310278, AY310279 \\
\hline & Rhinotus purpureus & Rpur & AY305476 & AY305612-AY305614 & AY305521 \\
\hline Platydesmida & Platydesmus sp. & Pla & AF240806 & AF240946-AF240948 & AY310280 \\
\hline Siphonophorida & Siphonocybe sp. & Siph & AY310178 & AY310228-AY310230 & AY310286 \\
\hline \multirow[t]{3}{*}{ Polydesmida } & Docodesmus trinidadensis & Dotr & AY310169 & AY310193-AY310195 & AY310255 \\
\hline & Pseudopolydesmus serratus & Xys1 & AF240814 & AF240970-AF240972 & AY310297, AY310298 \\
\hline & Oxidus gracilus & Ogr2 & AF240801 & AF240931-AF240933 & AY310272 \\
\hline \multirow[t]{3}{*}{ Spirobolida } & Hiltonius sp. & Hil & AF240797 & AF240918-AF240920 & AY310262, AY310263 \\
\hline & Narceus americanus & Nam & U90053 & U90039, AF240927 & AY310269 \\
\hline & Orthocricus sp. & Spil & AF240809 & AF240955-AF240957 & AY310289 \\
\hline Stemmiulida & Stemmiulus insulanus & Stem & AY310179 & AY310231-AY310233 & AY310291 \\
\hline \multirow[t]{2}{*}{ Sphaerotheriida } & Globotherium sp. (Madagascar) & Glo2 & AF240794 & AF240909-AF240911 & AY310256 \\
\hline & Sphaerotherium punctulatum (S. Africa) & $\mathrm{Sph} 2$ & AF240808 & AF240952-AF240954 & AY310287, AY310288 \\
\hline Glomerida & Glomeris marginata & Gma2 & AF240795 & AF240912-AF240914 & AY310257 \\
\hline Glomeridesmida & Glomeridesmus trinidadensis & Gtri & AY310170 & AY310196-AY310198 & AY310258 \\
\hline \multirow[t]{3}{*}{ Polyxenida } & Phryssonotus sp. & jump & AY310172 & AY310202-AY310204 & AY310265 \\
\hline & Polyxenus fasciculatus & Pol & U90055 & AF139001, AF139002 & AF240826 \\
\hline & Plesioproctus comans & Lop & AY310174 & AY310215-AY310217 & AY310268 \\
\hline \multicolumn{6}{|l|}{ Chilopoda: } \\
\hline \multirow[t]{8}{*}{ Geophilomorpha } & Ribautia sp. & Rib & AY310175 & AY310219-AY310221 & AY310282 \\
\hline & Strigamia bothriopa & Sbo3 & AY310177 & AY310225-AY310227 & AY310284 \\
\hline & Tuoba sydneyensis & Tlat & AY310181 & AY310237-AY310239 & AY310295 \\
\hline & Pachymerium ferrugineum & Pte & AF240807 & AF240949, AF240950 & AY310281 \\
\hline & Geophilus vittatus & Gvi & AF240796 & AF240915, AF240916 & AY310259 \\
\hline & Tasmanophilus spinatus & Tas & AY310180 & AY310234-AY310236 & AY310294 \\
\hline & Zelanion antipodus & Zan & AY310183 & AY310243-AY310245 & AY310299, AY310300 \\
\hline & Ballophilus australiae & Bau & AY310167 & AY310187-AY310189 & AY310247 \\
\hline Lithobiomorpha & Bothropolys multidentatus & $\mathrm{Bmu}$ & AF240789 & AF240896-AF240898 & AY305492 \\
\hline & Pokabius bilabiatus & $\mathrm{Pbi}$ & AF240804 & AF240938-AF240940 & AY310276 \\
\hline & Lithobius forficatus & Lfo_A & AF240799 & AY310209-AY310211 & AY310267 \\
\hline & Lithobius forficatus & Lfo_B & AF240799 & AY310212-AY310214 & AY310267 \\
\hline & Australobius scabrior & Aus & AY310166 & AY310184-AY310186 & AY310246 \\
\hline & Anopsobius neozelanicus & Ane & AY305459 & AY305538-AY305540 & AY305489 \\
\hline & Henicops maculatus & Hen & AY310171 & AY310199-AY310201 & AY310260, AY310261 \\
\hline & Lamyctes emarginatus & Lam & AY310173 & AY310205-AY310207 & AY310266 \\
\hline & Paralamyctes grayi & Para & AY305475 & AY305607-AY305609 & AY305519 \\
\hline Scolopendromorpha & Scolopendra polymorpha & Spo & AF137393 & AF139006, AF139007 & AF240828 \\
\hline & Scolopendra viridis & Svi & AF240812 & AF240964-AF240966 & AY310293 \\
\hline & Cormocephalus monteithi & $\mathrm{Cmo}$ & AY310168 & AY310190-AY310192 & AY310251 \\
\hline & Rhysida nuda & Rnu & AY310176 & AY310222-AY310224 & AY310283 \\
\hline & Scolopocryptops sexspinosus & Sse & AF240810 & AF240958-AF240960 & AY310290 \\
\hline & Theatops posticus & Tpo & AY310182 & AY310240-AY310242 & AY310296 \\
\hline & Cryptops hyalinus & Chy & AF240790 & AF240899, AF240900 & AY310248 \\
\hline Scutigeromorpha & Scutigera coleoptrata & Scol & U90057 & U90042, AF240951 & AY310285 \\
\hline & Thereuonema sp. & The & AY305478 & AY305619-AY305621 & AY305523 \\
\hline Craterostigmomorpha & Craterostigmus tasmanianus & Ctas & AF240793 & AF240907, AF240908 & AY310253, AY310254 \\
\hline
\end{tabular}


Table 1 (continued)

\begin{tabular}{|c|c|c|c|c|c|}
\hline \multirow[t]{2}{*}{ Higher classification } & \multirow[t]{2}{*}{ Taxon } & \multirow{2}{*}{$\begin{array}{l}\text { Lab } \\
\text { code }\end{array}$} & \multicolumn{3}{|c|}{ GenBank Accession No. } \\
\hline & & & $\mathrm{EF}-1 \alpha$ & Pol II & $\mathrm{EF}-2$ \\
\hline \multicolumn{6}{|l|}{ Pauropoda: } \\
\hline Pauropodidae & Allopauropus proximus & Apr & AY305460 & AY305541-AY305543 & AY305490 \\
\hline Eurypauropodidae & Eurypauropus spinosus & Eury & AY305463 & AY305559-AY305561 & AY305498 \\
\hline \multicolumn{6}{|l|}{ Symphyla: } \\
\hline \multirow[t]{2}{*}{ Scutigerellidae } & Hanseniella sp. & Han & U90049 & AF138982, AF249017 & AY305501 \\
\hline & Scutigerella sp. & Scu2_3 & AF137392 & AF139003-AF139005 & AF240827 \\
\hline Scolopendrellidae & Symphylella sp. & Sym & AF240813 & AF240967-AF240969 & (no EF-2 sequence) \\
\hline \multicolumn{6}{|l|}{ Outgroup } \\
\hline \multicolumn{6}{|l|}{ Pancrustacea: } \\
\hline Ostracoda & Cypridopsis vidua & Ost & AF063414 & AF138997-AF138999 & AF240825 \\
\hline Branchiopoda & Streptocephalus seali & ufs & AY305480 & AY305628-AY305630 & AY305526 \\
\hline Remipedia & Speleonectes tulumensis & Stu & AF063416 & AF139008-AF138010 & AF240829 \\
\hline Hexapoda & Tomocerus sp. & Tom & U90059 & AF139011, AF139012 & AF240830 \\
\hline \multicolumn{6}{|l|}{ Outgroup } \\
\hline \multicolumn{6}{|l|}{ Chelicerata: } \\
\hline \multirow[t]{2}{*}{ Xiphosura } & Carcinoscorpius rotundicauda & Cro & AF063407 & $\begin{array}{l}\text { AF138975, AF240983, } \\
\text { AF240984 }\end{array}$ & AY305496 \\
\hline & Limulus polyphemus & Lpo & U90051 & U90037 & AF20821 \\
\hline \multirow[t]{2}{*}{ Arachnida } & Mastigoproctus giganteus & Mga & U90052 & U90038 & AF240823 \\
\hline & Nipponopsalis abei & $\mathrm{Nab}$ & AF137391 & AF138993- AF138995 & AF240824 \\
\hline \multirow[t]{3}{*}{ Pycnogondida } & Colossendeis sp. & $\mathrm{Col}$ & AF063406 & $\begin{array}{l}\text { AF138974, AY305555, } \\
\text { AY305556 }\end{array}$ & AY305495 \\
\hline & Endeis laevis & Ele & AF063409 & $\begin{array}{l}\text { AF138981, AF240882, } \\
\text { AF240883 }\end{array}$ & AF240819 \\
\hline & Tanystylum orbiculare & Tor & AF063417 & AF139013, AF139014 & AF240831 \\
\hline
\end{tabular}

${ }^{a}$ Accession Nos. for each taxon by gene (upper row: EF-1 $\alpha$; middle row: Pol II; and lower row: EF-2).

outgroup Caenorhabditis elegans. This indel region, previously called region $I V$, has already been analyzed for three myriapods plus 24 non-myriapods (Regier and Shultz, 2001b). In this report, we increased taxon sampling for the region IV indel to 54 myriapods, six chelicerates (from 5), 32 pancrustaceans (from 10), five tardigrades (from 1), and two onychophorans (from 1). The number of nematodes sampled remained 1 . GenBank numbers can be found in Table 1; Regier and Shultz, 2001b; and Regier et al., 2004. The indel region was excluded from the sequence data set.

\subsection{Data analysis}

Parsimony analyses of amino acid and nucleotide data sets were conducted with PAUP*4.0 (Swofford, 1998) using equally weighted character transformations with third codon position characters excluded (see Regier and Shultz, 2001b for the rationale to omit third codon positions). Analysis consisted of a heuristic search using TBR branch swapping with random sequence addition (100 sequence-addition replicates). Non-parametric bootstrap analysis (1000 replications) was identical except for 10 sequence-addition replicates per bootstrap replication. Partitioned Bremer support values (Baker and DeSalle, 1997) were calculated using TreeRot software (version 2C; Sorenson, 1999).
Likelihood-based analyses of amino acid and nucleotide (minus third codon position) data sets were performed with MrBayes (version 3.0; Huelsenbeck and Ronquist, 2001). Both amino acid and nucleotide analyses were replicated with ngen (i.e., number of generations) $=2 \times 10^{7}$, samplefreq (i.e., frequency of sampling the generations) $=100$, burnin (i.e., initial number of generations disregarded $)=10^{7}$ generations (with apparent stationarity reached after several hundred thousand generations). For the amino acid analyses, aamodel (i.e., model of amino acid substitution) = jones (Jones et al., 1992). For the nucleotide analyses, nst (i.e., number of rate categories) $=6$ (i.e., general time reversible model) and rates (i.e., method of accomodating among-site-ratevariation) $=$ invgamma (i.e., variation fitted to a discrete gamma distribution plus a separate parameter for invariant sites). The same favored nucleotide model (i.e., general time reversible + gamma + invariant) was chosen by a hierarchical likelihood ratio test and by the Akaike Information criterion, as implemented in Modeltest (version 3.06; Posada and Crandall, 1998).

\section{Results}

Bayesian (Fig. 1) and parsimony (Fig. 2) analyses of combined EF-1 $\alpha$, Pol II, and EF-2 sequences from 59 
A

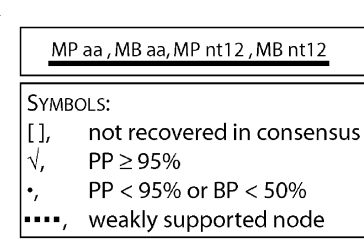

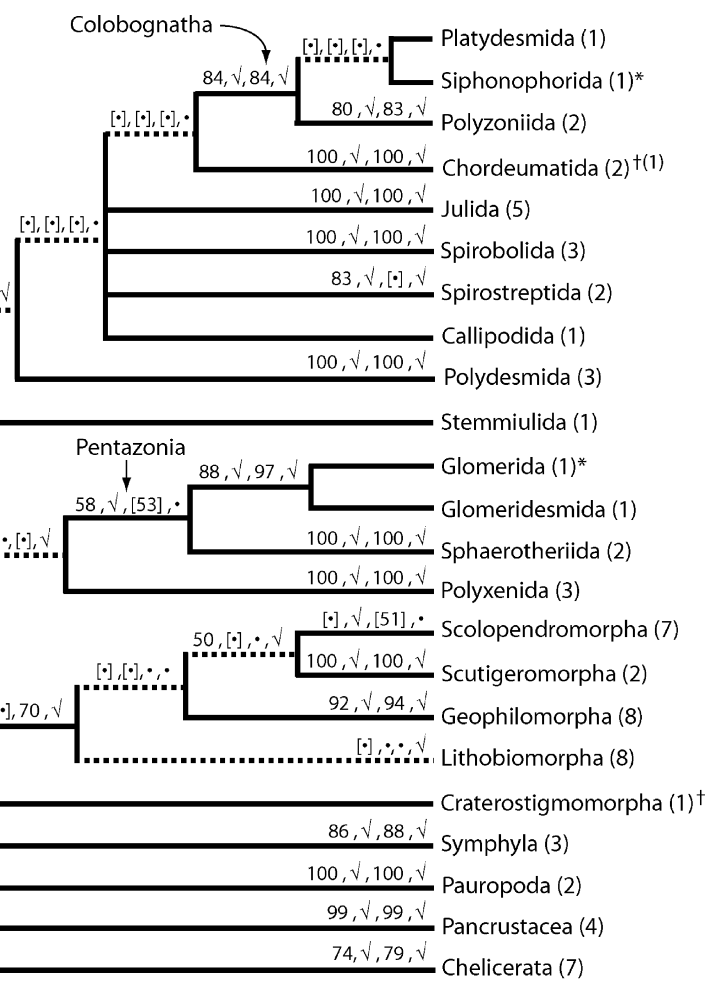

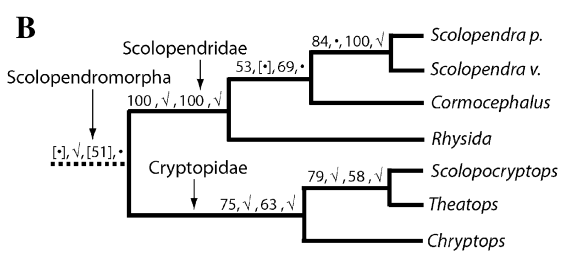
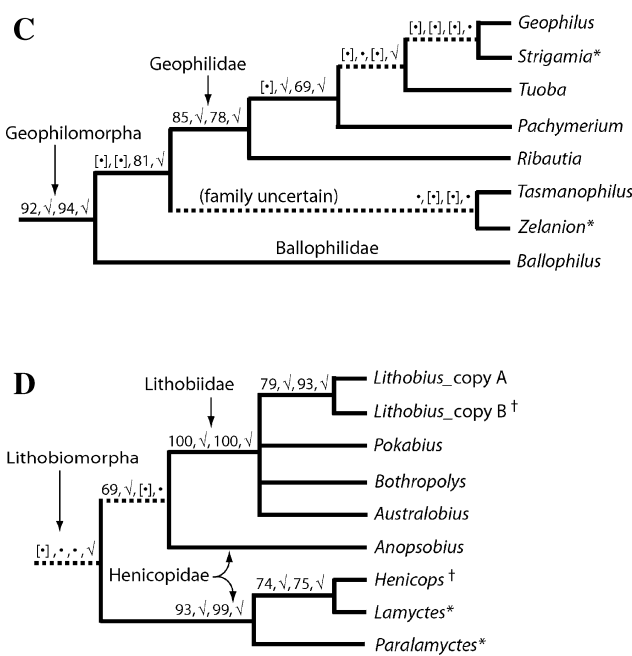

$\mathbf{E}$

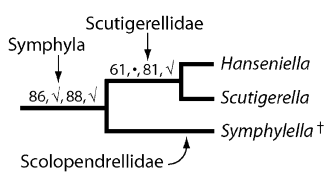

F

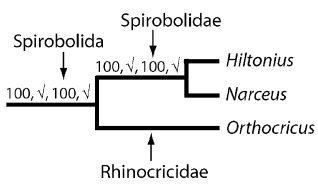

G

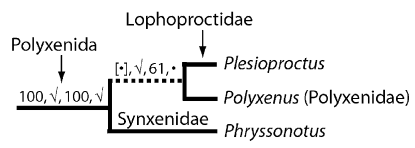

$\mathbf{H}$
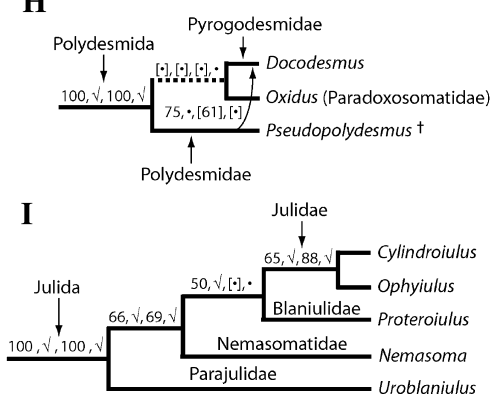

Fig. 1. Topology of myriapod relationships inferred from Bayesian phylogenetic analysis of nucleotides with third codon positions excluded. The resulting 50\% majority-rule consensus is shown in nine parts for clarity of presentation. Relationships within outgroups are not shown. (A) Terminal taxa are represented by order (for Diplopoda and Chilophoda), class (for Symphyla and Pauropoda), or infra-phylum (for Pancrustacea and Chelicerata) with the number of species in each terminal taxon shown in parentheses. (B-I) Phylogenetic relationships within terminal taxa shown in part (A) that represent three or more species. Node support indicators are displayed above branches in the following order: (1) BP value for parsimony analysis of amino acids, (2) posterior probability $\geqslant 95 \%(\& \# x 221 \mathrm{~A}$;) or $<95 \%(-)$ for Bayesian analysis of amino acids, (3) BP value for parsimony analysis of nucleotides with third codon positions excluded, and (4) posterior probability $\geqslant 95 \%(\& \# x 221 \mathrm{~A}$; ) or $<95 \%(\bullet)$ for Bayesian analysis of nucleotides with third codon positions excluded. Brackets indicate that the node was not recovered in that particular analysis. Dashed lines identify weakly supported nodes. For the EF-2 indel (see text) in chilopods and diplopods only, character state assignments were +6 for 44 taxa (not marked), +3 or 0 for six taxa (taxon names followed by *), and undetermined for five taxa (taxon names followed by $\dagger$ ). 


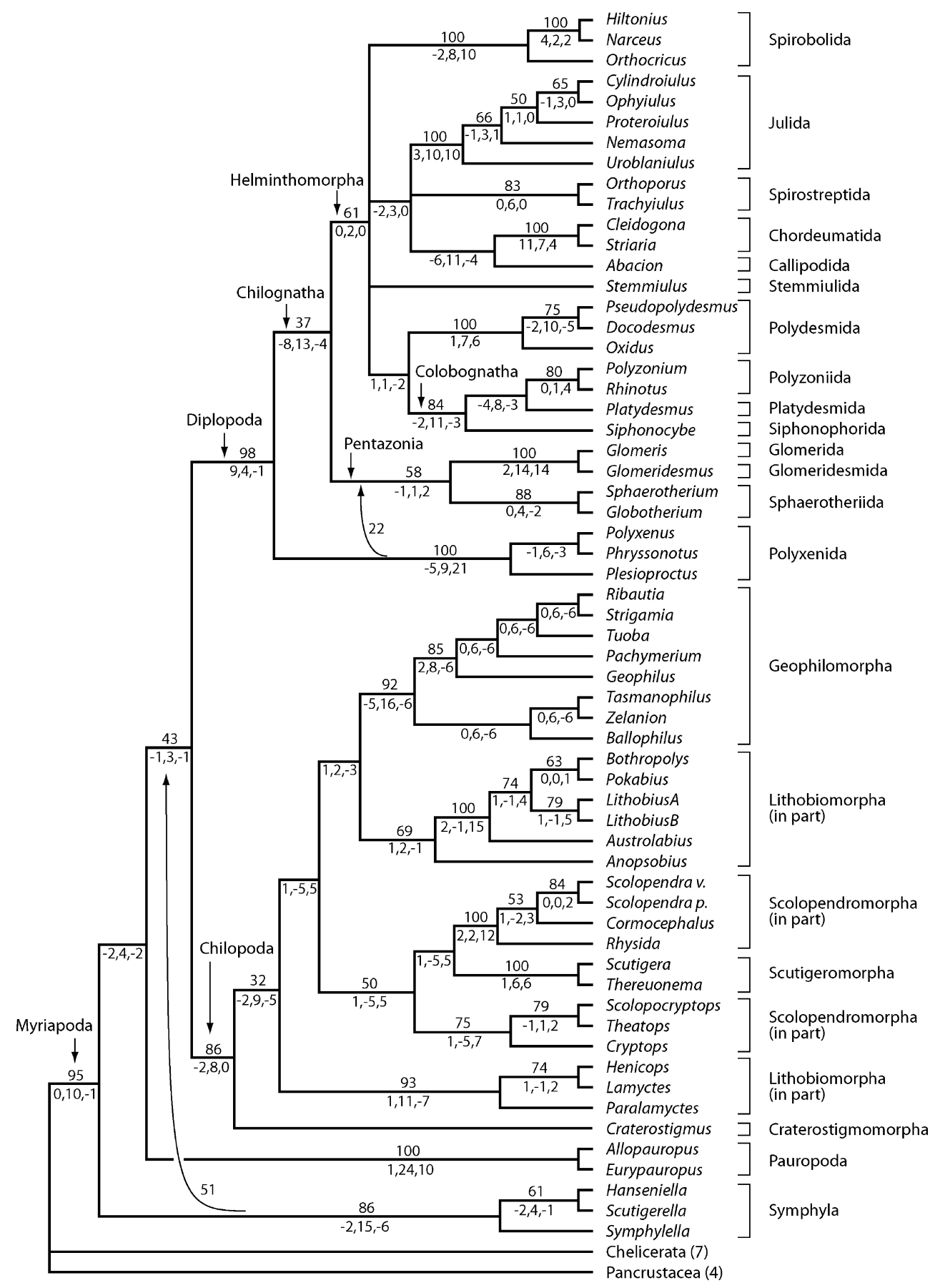

Fig. 2. Strict consensus of myriapod relationships inferred from parsimony analysis of amino acids. Relationships within outgroups are not shown. BP values are placed above internal branches and partitioned Bremer support below $(E F-1 \alpha, P o l$ II, and $E F-2)$; the latter is based on analysis of one of the seven most-parsimonious trees. BP values for two less-parsimonious groups are shown beside the elongated arrows. Tree statistics from MPaa analysis: number of most-parsimonious trees $=7$; tree length $=4204$; number of parsimony-informative characters $=504$; consistency index $=0.3749$; retention index $=0.5741$. For comparison, the tree statistics from the MPnt12 analysis (tree not shown but its topology can be largely inferred from Fig. 1) are: number of most-parsimonious trees $=4$; tree length $=7159$; number of parsimony-informative characters $=881$; consistency index $=0.2352$; retention index $=0.5154$.

diverse myriapod species plus 11 pancrustacean and chelicerate outgroups yielded some supra-ordinal relationships that were consistently recovered and strongly supported, as indicated by non-parametric bootstrap percentages (BP). These were Myriapoda (BP up to 95\%), Diplopoda (BP up to 98\%), Chilopoda (BP up to $86 \%$ ), Pauropoda (BP, $100 \%$ ), Symphyla (BP up to $88 \%$ ), Helminthomorpha (BP up to $90 \%$ ), Colobognatha (BP 
up to $84 \%$ ), and Glomerida + Glomeridesmida (BP up to 97\%). Pentazonia (Diplopoda) and 'ChilopodaCraterostigmomorpha' and a 'Scutigeromorpha + Scolopendromorpha' clade received moderate support. All other supra-ordinal relationships, including those among classes, were inconsistently recovered across the four approaches and had low BP values. Partitioned Bremer support showed gene-specific and variable levels of support across groups.

Within Diplopoda, all eight multiply-sampled orders were consistently recovered and strongly supported. Within Chilopoda, two of the four multiply sampled orders (i.e., Scutigeromorpha and Geophilomorpha) received strong support. Within orders and Symphyla, numerous supra-generic relationships were consistently recovered and strongly supported (Fig. 1B-I).

A single, informative, three-state indel was identified from the multi-taxon alignment of EF-2 sequences (Fig. $3 \mathrm{~A})$. Most relevant, the +6 character state was uniquely restricted to chilopods and diplopods (i.e., 44 species). Of the five diplopods and chilopods with a different state, an examination of their phylogenetic positions (see taxon names followed by * in Fig. 1) suggested by parsimony that these resulted from four independent losses of the +6 state. Assuming ancestral states of +6 for Diplopoda and Chilopoda, and either 0 or +3 for Myriapoda (since the +6 state was not detected outside Myriapoda), the most-parsimonious distribution of this indel across Myriapoda was consistent with seven (Fig. 2B) out of the possible 15 rooted topologies that represent possible class relationships. These seven either had Pauropoda (three topologies) or Symphyla (three topologies) as the basal myriapod class or else made them sister taxa (one topology).

\section{Discussion}

\subsection{Monophyly of Myriapoda}

The status of myriapod monophyly is sometimes characterized as controversial due to a paucity of compelling morphological synapomorphies (Koch, 2003) as well as a persistent argument that hexapods are derived from a paraphyletic myriapod assemblage (e.g., Kraus, 2001). In our view, the status of Myriapoda is not problematic and the impression of controversy stems from attempts by some workers to give greater weight to inferences derived from subjective, induction-based Hennigian treatments than those derived from objective, quantitative analysis of morphological and molecular data (see Edgecombe and Giribet, 2002; Kusche et al., 2003; Regier and Shultz, 2001a; Shultz and Regier, 2000). Indeed, most molecule-based phylogenetic analyses place Hexapoda among crustaceans and recover multiply sampled myriapods as monophyletic (e.g.,

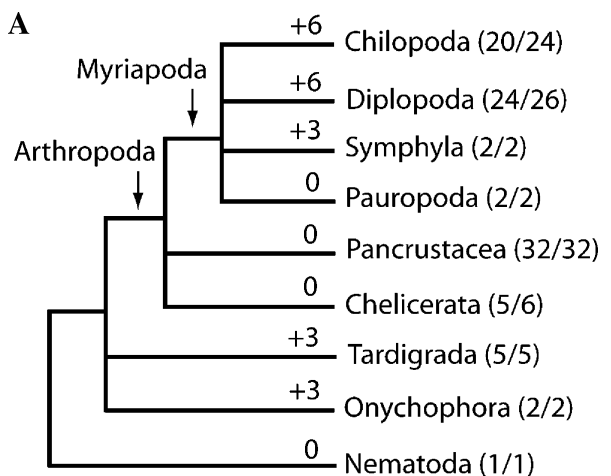

B
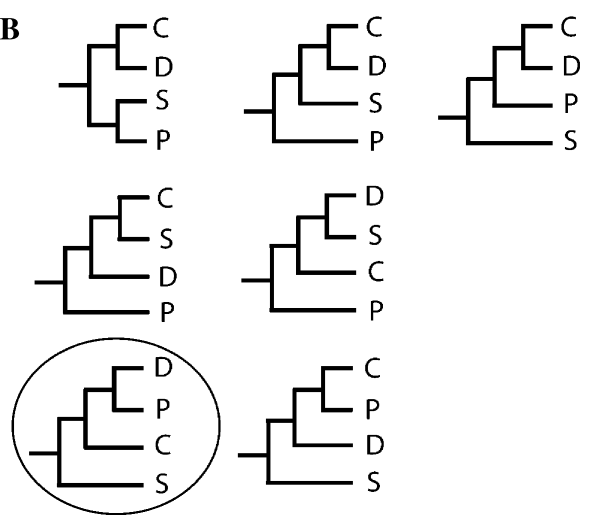

Fig. 3. Phylogenetic analysis of an indel character in the EF-2 gene. (A) Mapping the indel onto a partially resolved, rooted panarthropod phylogeny. Numbers $(0,+3$, and +6$)$ on terminal branches identify the lengths in nucleotides of the the insertion relative to that in the nematode Caenorhabditis elegans. Numbers in parentheses after the taxon name identify the number of taxa sampled that have the indicated indel character state followed by the total number sampled. See Fig. 1 and its legend to identify the six diplopod and chilopod taxa with non+6 state assignments and the six taxa for which data are missing. One of three pycnogonids (out of six chelicerates sampled) has the +3 state. (B) Seven most-parsimonious topologies that describe myriapod class relationships, assuming ancestral states of +6 for Chilopoda and Diplopoda, and either 0 or +3 for Myriapoda. The other eight less-parsimonious topologies were all one step longer (three versus two) and are not shown. The one favored topology that is also consistent with Dignatha ( = Diplopoda + Pauropoda) is circled. C, Chilopoda; D, Diplopoda; P, Pauropoda; S, Symphyla.

Boore et al., 1998; Friedrich and Tautz, 1995; Giribet et al., 2001; Mallatt et al., 2004; Regier and Shultz, 2001b; Shultz and Regier, 2000). In short, we contend that morphology has provided neither unambiguous myriapod synapomorphies nor a compelling alternative to myriapod monophyly and, in contrast, that molecular evidence (particularly Pol II but also supported by EF$1 \alpha$ and Pol II; see Figs. 1A, and 2) has provided convincing evidence favoring myriapod monophyly. This situation reflects neither a phylogenetic controversy nor a conflict between morphological and molecular evidence.

\subsection{Relationships among myriapod classes}

Morphology-based analyses consistently unite Diplopoda and Pauropoda in a group, Dignatha (Fig. 4), and 


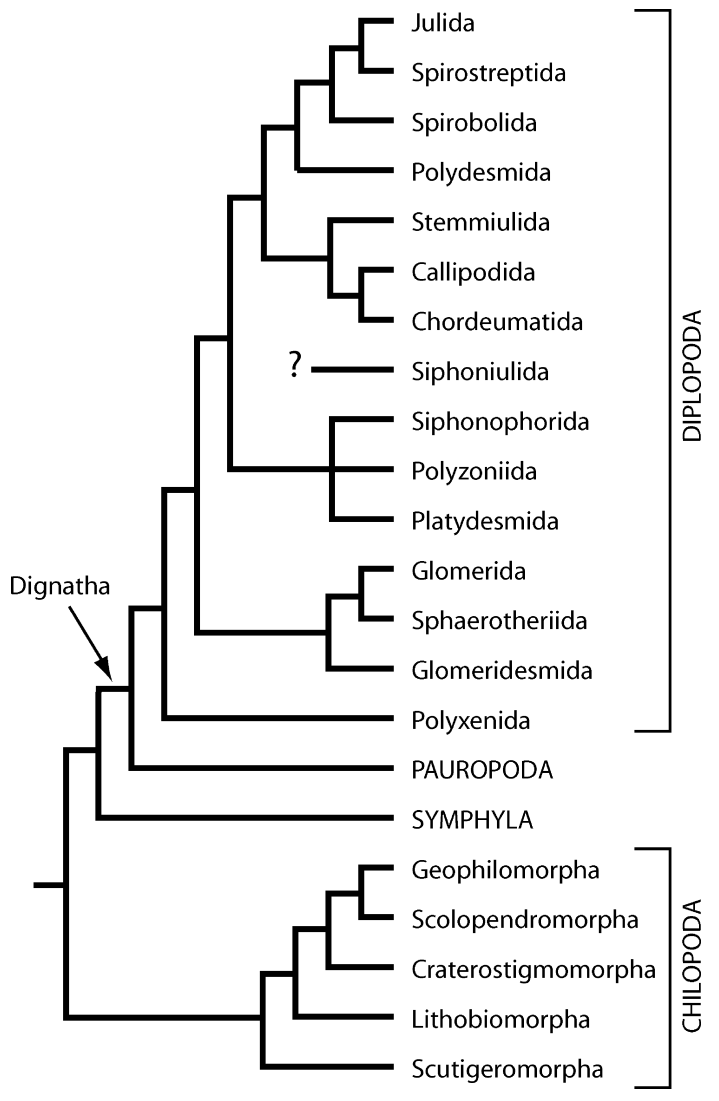

Fig. 4. Working hypothesis of myriapod relationships based on morphology. Relationships within Diplopoda follow Enghoff et al. (1993) and relationships within Chilopoda follow Dohle (1985) and Edgecombe and Giribet (2002).

its supporting synapomorphies (collum, gnathochilarium, ventral tracheal stigmata) are convincing. Morphologists also tend to place Dignatha and Symphyla in a clade, Progoneata, named for the supposedly derived anterior placement of the gonopore. However, polarity of the progoneate condition is uncertain given a comparable segmental position of the genital opening in nonmyriapods, notably Chelicerata (Regier and Shultz, 2001a). Furthermore, the supposedly plesiomorphic posterior genital opening, or opisthogoneate condition, in Chilopoda is unusual in Arthropoda and, for purposes of this study, effectively autapomorphic. The posterior gonopore of chilopods gains phylogenetic currency only when the opisthogoneate hexapods are regarded as divergent myriapods or as the myriapod sister group, neither of which appears likely given results of recent molecule-based analyses (see above). Progoneates share other morphological features (e.g., unusual trichobothria, yolk deposited in fat body) (Dohle, 1988), but their phylogenetic value has not been specifically addressed by modern quantitative analysis of a relevant sample of arthropod diversity.

Our own analyses of sequence characters yield topologies of unstable class relationships and of low node support. However, we have identified an indel in the EF2 gene that is consistent with seven of the possible 15 topologies that describe myriapod class relationships (Fig. 2). Of these seven, one (see circled topology in Fig. 3B) includes Dignatha; the other two topologies with Dignatha (not shown) are disfavored. Of course, this indel is but a single character, and there is some (but not much) homoplasy, so we remain circumspect about relationships among Dignatha, Symphyla, and Chilopoda.

\subsection{Relationships within Diplopoda}

Recent morphology-based studies of ordinal relationships within Diplopoda rely heavily on the seminal cladistic analyses of Enghoff (1984) and Enghoff et al. (1993) (Fig. 4). Sierwald et al. (2003) took a parsimonybased approach using a data matrix based largely on Enghoff's characters but also added the enigmatic order Siphoniulida, which previously had not been known in sufficient detail. With Siphoniulida excluded from the analysis, the preferred cladogram did not differ significantly from that of Enghoff et al. (1993) (Fig. 4) except that Polydesmida was reconstructed as the sister group of Nematophora (Stemmiulida + Callipodida + Chordeumatida) instead of Juliformia (Julida + Spirobolida + Spirostreptida). When Sierwald et al. included Siphoniulida, Nematophora collapsed and Juliformia emerged as the sister group to Colobognatha (Polyzoniida + Siphonophorida + Platydesmida), and Siphoniulida and Chordeumatida formed the sister group to the remaining Chilognatha.

Our analysis is currently the most ambitious attempt to resolve diplopod ordinal relationships using molecular characters (28 taxa representing 14 of the 15 extant orders) and was undertaken with the goal of resolving the many open questions in millipede phylogeny. We recovered all multiply sampled orders and found strong to moderate support for three interordinal groups recognized by Enghoff (1984) (namely, Pentazonia, Helminthomorpha, and Colobognatha) but failed to resolve diplopod phylogeny completely (Figs. 1 and 2). Still, monophyly of Pentazonia and Colobognatha has been controversial based on morphological evidence, and results of our analysis are noteworthy in this context.

Pentazonia $(=$ Glomeridesmida + Glomerida + Sphaerotheriida) was united by Enghoff (1984) on the presence of divided "sternites" and posterior telopods in the male. However, it is likely that the "sternites" of diplopods are actually leg bases rather than elements of the body wall (both "sternites" of diplopods and coxae of pauropods bear the tracheal openings), which would make the "separated" condition plesiomorphic. Telopods appear to have existed in the extinct non-pentazonian Microdecemplex (Arthropleuridea) (Wilson and Shear, 2000), which suggests that this character is symplesiomorphic for Pentazonia, as well. Conse- 
quently, molecular evidence for monophyly of Pentazonia is significant, although the strongly supported separation of the enrolling oniscomorph or pill millipedes (Glomerida and Sphaerotheriida) by Glomeridesmida is unexpected and seemingly in conflict with the complex skeletomuscular similarities of oniscomorphs (H. Wilson, personal observations).

Colobognatha $\quad(=$ Polyzoniida + Platydesmida + Siphonophorida) was strongly supported by our analysis, although it is one of the more controversial supraordinal groups based on external morphological characters. Enghoff (1984) and Sierwald et al. (2003) united Colobognatha with several characters including eight pre-gonopodial leg pairs in the male, reduced head and simplified mandibles, first instars with four pairs of legs, egg-brooding behavior, and elongate sub-tubular defensive glands, but many of these characters are problematic. The egg-brooding behavior has been confirmed in only two of the orders and is practiced by different sexes, and the number of legs in the first instar has only been confirmed in two orders. Hoffman (1979) had previously suggested that simple, leg-like gonopods are symplesiomorphic in colobognathans, as it is likely the primitive condition for Helminthomorpha, and the presence of simple gonopods in Palaeozoic archipolypodans, hypothesized to form the sister group to Helminthomorpha (Wilson and Anderson, 2004), supports his contention. Hoffman also questioned the validity of a reduced head and mandibles, citing the wide spectrum of modification ranging from the prolonged 'beak' of the Siphonophorida to the more typical mandibles and gnathochilarium in the Platydesmida. The strong support of our data for a monophyletic Colobognatha is therefore significant.

Our results failed to recover some groups that are considered well supported by morphology (e.g., Nematophora, Juliformia) but they provide some insights into relationships within orders. For example, our analysis included representatives from all five julid superfamilies recognized by Enghoff (1991). Our results corroborate the relationships Enghoff proposed and even resolved the sole trichotomy in his system (Blaniuloidea + Nemasomatoidea + Juloidea) by reconstructing the Blaniuloidea (i.e., Proteroiulus) as the sister group to Julidae (i.e., Cylindroiulus + Ophyiulus) (Fig. 1I). In addition, we recovered the two representative spirostreptids, Trachyiulus (Cambalopsidae) and Orthoporus (Spirostreptidae), as monophyletic, which conflicts with a proposal that Spirostreptida is paraphyletic, with the families Cambalopsidae and Cambalidae together forming the sister group to Julida (Mauriès, 1987).

\subsection{Relationships within Chilopoda}

Myriapodologists widely accept the chilopod interordinal relationships illustrated in Fig. 4 (Dohle, 1985) and the molecule-based analyses of Edgecombe, Giribet and co-workers (Edgecombe and Giribet, 2002, 2004; Edgecombe et al., 1999) tend to corroborate this hypothesis. In contrast, our analysis recovers Chilopoda and its constituent orders but offers little robust phylogenetic resolution among orders. However, our data moderately support two improbable relationships, a basal position for Craterostigmomorpha and a Scutigeromorpha + Scolopendromorpha clade. Below we discuss the implications of our results for subordinal relationships within the widely acknowledged clades Lithobiomorpha, Scolopendromorpha, and Geophilomorpha.

Lithobiomorpha is the only chilopod order in which monophyly has been seriously questioned (see review by Edgecombe and Giribet (2002)), due primarily to the lack of compelling morphological synapomorphies rather than significant evidence that some lithobiomorph lineage is more closely allied to some nonlithobiomorph group (see review by Edgecombe (2004)). Likewise, our analyses provide little evidence germane to the problem. In contrast, Edgecombe and Giribet (2002, 2004) have provided compelling evidence favoring the monophyly of the order and supporting the existence of two monophyletic sister families, Lithobiidae and Henicopidae. Our results support monophyly of Lithobiidae but recover a paraphyletic Henicopidae, with Anopsobius being reconstructed (albeit weakly) as the sister group to Lithobiidae (Fig. 1D).

Monophyly of the Scolopendromorpha received modest support from our analysis but is well supported by others (e.g., Edgecombe and Giribet, 2004; Edgecombe et al., 1999). Our analyses also recover two monophyletic families, Scolopendridae and Cryptopidae sensu Attems (1930) (Fig. 1B), a finding also reached by the combined morphology/molecule study of Edgecombe and Giribet (2004). In contrast, the internal topology of Cryptopidae recovered in our analysis (i.e., Cryptops (Theatops, Scolopocryptops)) is inconsistent with that of Edgecombe and Giribet (2004) (as well as Edgecombe and Giribet, 2004; Kohlrausch, 1881; Schileyko, 1992, 1996; Schileyko and Pavlinov, 1997; Shelley, 2002), which placed those taxa with the apparently plesiomorphic "scolopendrid" character of 21 leg pairs (e.g., Cryptops, Theatops) in one group and those with 23 pairs (e.g., Scolopocryptops) in another.

Monophyly of the Geophilomorpha is strongly supported by our analyses (Fig. 1A), but internal relationships are ambiguous (Fig. 1C). This result is a recurring theme in studies of the order. Still, our results are congruent with the morphology-based analysis of Foddai and Minelli (2000) and the combined analysis of Edgecombe and Giribet (2002) in recovering Ballophilus (Ballophilidae) as distinctly separate from the heterogeneous "Geophilidae." However, "Geophilidae" was recovered as paraphyletic by Edgecombe and Giribet (2004). 


\subsection{Phylogenetic signal and the temporal structure of phylogenetic diversification}

In their molecule-based study of myriapod phylogeny, Regier and Shultz (2001a) suggested that their inability to resolve relationships among classes and orders was caused by heterogeneity in the temporal pattern of phylogenetic diversification. Specifically, they speculated that the myriapod classes diverged from one another in a relatively short time, such that few phylogenetically informative substitutions could accumulate. A similar radiation of orders within classes, perhaps in association with the origin of terrestriality, might explain difficulties in resolving ordinal relationships. In contrast, longer intervals preceeding and between radiation events and the long period of independent evolution following ordinal radiation would produce stronger phylogenetic signals as substitutions accumulated. Regier and Shultz (2001a) reviewed the fossil record of Myriapoda but felt that it was too incomplete and provided little relevant information. However, recent advances in the fossil record of Diplopoda allow us to place some constraints on the origination time of certain clades and to infer relative rates of phylogenetic diversification. Advances in the fossil record of plants have also yielded some corroborating evidence.

New Paleozoic millipedes have recently been described that significantly extend the stratigraphic range of several taxa. The oldest known millipedes have been described from the mid-Silurian (Wenlock, 425 million years ago) of Cowie Harbour, Scotland (Wilson and Anderson, 2004). These millipedes were fully terrestrial, as evidenced by paired sternal spiracles, had gonopods, and belong to the extinct clade Archipolypoda that was suggested by Wilson and Anderson (2004) to either represent basal Chilognatha or the sister group to extant Chilognatha. Additionally, a mid-Silurian fossil with colobognathan affinities has been identified from the Wenlock of the Hagshaw Hills inlier of the Midland Valley of Scotland (Wilson, 2005). Previously, the oldest known millipedes with colobognathan affinities were the Upper Carboniferous ( $~ 300$ million years ago) pleurojulids (Wilson and Hannibal, 2005). Perhaps most significantly, juliform millipedes have recently been described from the Lower Devonian of Scotland (Pragian, 405 million years ago) and the Maritime Provinces of Canada (Emsian, 395 million years ago) (Wilson, in review). Juliformia (Julida + Spirobolida + Spirostreptida) is universally regarded by myriapodologists as the most derived clade of millipedes.

The oldest evidence for land plants (which is taken here as a proxy for evidence of a diplopod-friendly terrestrial environment) takes the form of dispersed microscopic spores (cryptospores), the oldest of which come from the Middle Ordovician (Llanvirn, $\sim 475$ million years ago) of Saudi Arabia (Strother et al., 1996). These spores are abundant and globally distributed from the Ordovician, decreasing in abundance through the Silurian and Lower Devonian, and have been suggested to be from early relatives of the bryophytes (Wellman and Gray, 2000). This interpretation was once controversial because there was little direct evidence of the parent plants. However, spore-containing plant fragments from the Upper Ordovician (Caradoc, $\sim 450$ million years ago) of Oman have recently been described that appear to have liverwort affinities (Wellman et al., 2003), supporting the bryophyte affinity of dispersed cryptospores. The first unequivocal macroscopic plant remains do not appear in the fossil record until the Silurian (Wenlock, $\sim 425$ million years ago) (Edwards and Feehan, 1980). Thus, there is a significant lag of approximately 50 million years between the appearance of the first dispersed spores and fossils of relatively complete land plant megafossils. During this time the vegetation was widespread, but of limited diversity and underwent very little evolutionary change, at least as indicated by spores, until the late Llandovery (Wellman and Gray, 2000). In the late Llandovery many types of cryptospore disappear from the fossil record and trilete spores appear. It has been suggested that the inception of trilete spores reflects the first appearance of tracheophytes (Edwards and Wellman, 2001). Following this major turnover in spore types, trilete spores underwent a major diversification, by inference reflecting a diversification in early tracheophytes.

The presence of terrestrial diplopod trace fossils in the Ordovician (Caradoc) (Johnson et al., 1994) indicates that myriapod terrestrialization was coeval with that of plants. It is possible to envision a scenario in which rapid evolutionary change in myriapods associated with terrestrialization and diversification into four classes is followed by a period of relatively little diversification in the Ordovician, mirroring that of plants. During this period, the diplopods would be represented by only a few basal lineages. By the Wenlock there is fossil evidence for Archipolypoda and colobognath-like millipedes and, using morphology-based phylogenies (Fig. 3), we can infer the presence of stem group Polyxenida, Arthropleuridea and Pentazonia. The first appearance of millipedes in the fossil record at the same time as a major diversification in tracheophyte plants may not be a coincidence. However, a relationship between these events is difficult to evaluate because the Ordovician through the early Silurian was a time of persistently high sea levels and relatively fewer continental deposits are known compared to the later Silurian and Devonian. Based on the presence of juliform millipedes in the Lower Devonian, we would predict that all other millipede clades arose between the mid-Silurian and the beginning of the Devonian. This would necessitate a rapid radiation in Diplopoda in the Silurian, again, mirroring that of the terrestrial vegetation. 
The pattern of diversification hypothesized above could explain the inability of EF- $1 \alpha$, Pol II and EF-2 sequences to resolve some diplopod relationships and not others. During the long period of relatively low diversification in the Ordovician, many substitutions may have accumulated leading to a large phylogenetic signal. During the Upper Silurian, cladogenesis may have been too rapid for sufficient substitutions to accumulate to yield a significant phylogenetic signal.

\section{Acknowledgments}

We thank Greg Edgecombe, Henrik Enghoff, Gonzalo Giribet, Robert Mesibov, Carles Ribera, Nobuo Tsurusaki, and Jill Yager for specimens, and Greg Edgecombe and Gonzalo Giribet for helpful comments. This study was supported by National Science Foundation Grant DEB-0075605. J.W.S. was supported by the Maryland Agricultural Experiment Station.

\section{Appendix A. Supplementary data}

Supplementary data associated with this article can be found, in the online version, at doi:10.1016/j.ympev. 2004.09.005

\section{References}

Attems, G., 1930. Myriapoda. 2: Scolopendromorpha. Das Tierreich, 54. Walter de Gruyter, Berlin 307pp.

Baker, R.H., DeSalle, R., 1997. Multiple sources of character information and the phylogeny of Hawaiian drosophilids. Syst. Biol. 46, 654-673.

Boore, J., L, Labrov, D.V., Brown, W.M., 1998. Gene translocation links insects and crustaceans. Nature 392, 667-668.

Dohle, W., 1985. Phylogenetic pathways in the Chilopoda. Bijdr. Dierk. $55,55-66$.

Dohle, W., 1988. Myriapoda and the Ancestry of Insects. Manchester Polytechnic, Manchester.

Edgecombe, G.D., 2004. Monophyly of Lithobiomorpha (Chilopoda): new characters from pretarsal claws. Insect Syst. Evol. 35, 29-41.

Edgecombe, G.D., Giribet, G., 2002. Myriapod phylogeny and the relationships of Chilopoda. In: Llorente Bousquets, J., Morrone, J.J. (Eds.), Biodiversidad, Taxonomía y Biogeographia de Artrópodos de México: Hacia una Síntesis de su Conocimiento. Universidad Nacional Autómoma de México, Prensas de Ciencias, pp. $143-168$.

Edgecombe, G.D., Giribet, G., 2004. Adding mitochondrial sequence data (16S rRNA and cytochrome $c$ oxidase subunit I) to the phylogeny of centipedes (Myriapoda: Chilopoda): an analysis of morphology and four molecular loci. J. Zool. Syst. Evol. Res. 42, 89-134.

Edgecombe, G.D., Giribet, G., Wheeler, W.C., 1999. Phylogeny of Chilopoda: analysis of $18 \mathrm{~S}$ and 28S rDNA sequences and morphology. In: Melic, A., et al. (Eds.), Evolución y filogenia de Arthropoda. Boletín S.E.A. vol. 26, pp. 293-331.

Edwards, D., Feehan, J., 1980. Records of Cooksonia-type sporangia from late Wenlock strata in Ireland. Nature 287, 41-42.
Edwards, D., Wellman, C.H., 2001. Embryophytes on land: the Ordovician to Lochkovian (Lower Devonian) record. In: Gensel, P.G., Edwards, D. (Eds.), Plants Invade the Land. Columbia University Press, New York, pp. 3-28.

Enghoff, H., 1984. Phylogeny of millipedes - a cladistic analysis. Z. Zool. Syst. Evolut.-Forsch. 22, 8-26.

Enghoff, H., 1991. A revised cladistic analysis and classfication of the millipede order Julida, with establishment of four new families and description of a new nemasomatoid genus from Japan. Z. Zool. Syst. Evolut.-Forsch. 29, 241-263.

Enghoff, H., Dohle, W., Blower, J.G., 1993. Anamorphosis in millipedes (Diplopoda): the present state of knowledge with some developmental and phylogenetic considerations. Zool. J. Linnean Soc. 109, 103-234.

Foddai, D., Minelli, A., 2000. Phylogeny of geophilomorph centipedes: old wisdom and new insights from morphology. Fragmenta Faunistica Suppl. 43, 61-71.

Friedrich, M., Tautz, D., 1995. Ribosomal DNA phylogeny of the major extant arthropod classes and the evolution of myriapods. Nature 376, 165-167.

Giribet, G., Edgecombe, G.D., Wheeler, W.C., 2001. Arthropod phylogeny based on eight molecular loci and morphology. Nature $413,157-161$.

Hilken, G., Kraus, O., 1994. Struktur und Homologie der Komponenten des Gnathochilarium der Chilognatha (Tracheata, Diplopoda). Verh. Natur. Ver. Hamburg 34, 33-50.

Hoffman, R.L., 1979. Classification of the Diplopoda. Muséum d'Histoire Naturelle, Genève 237 pp.

Huelsenbeck, J.P., Ronquist, F., 2001. MrBayes: Bayesian inference of phylogeny. Bioinformatics 1, 754-755.

Johnson, E.W., Briggs, D.E.G., Suthren, R.J., Wright, J.L., Tunnicliff, S.P., 1994. Non-marine arthropod traces from the subaerial Ordovician Borrowdale Volcanic Group, English Lake District. Geol. Mag. 131, 395-406.

Jones, D.T., Taylor, W.R., Thornton, J., 1992. The rapid generation of mutation data matrices from protein sequences. Comput. Appl. Biosci. 8, 275-287.

Koch, M., 2003. Monophyly of the Myriapoda? Reliability of current arguments. African Invertebrates 44, 137-153.

Kohlrausch, E., 1881. Gattungen und Arten der Scolopendriden. Arch. Naturg. 47, 50-132.

Kraus, O., 1998. Phylogenetic relationships between higher taxa of tracheate arthropods. In: Forety, R.A., Thomas, R.H. (Eds.), Arthropod Relationships. Chapman \& Hall, London, pp. 295303

Kraus, O., 2001. "Myriapoda" and the ancestry of the Hexapoda. Ann. Soc. Entomol. France (N.S.) 37, 105-127.

Kusche, K., Hembach, A., Hagner-Holler, S., Gebauer, W., Burmester, T., 2003. Complete subunit sequences, structure and evolution of the $6 \times 6$-mer hemocyanin from the common house centipede, $\mathrm{Scu}$ tigera coleoptrata. Eur. J. Biochem. 270, 2860-2868.

Maddison, W.P., Maddison, D.R., 1992. MacClade: Analysis of phylogeny and character evolution, version 4.04 for Mac OS X. Sinauer, Sunderland, MA.

Mallatt, J.M., Garey, J.R., Shultz, J.W., 2004. Ecdysozoan phylogeny and Bayesian inference: first use of nearly complete $28 \mathrm{~S}$ and $18 \mathrm{~S}$ rRNA gene sequences to classify the arthropods and their kin. Mol. Phylogen. Evol. 31, 178-191.

Mauriès, J.-P., 1987. Cambalides nouveaux et peu connus d'Asie, d'Amérique et d'Océanie. II. Pseudoannolenidae, Choctellidae (Myriapoda, Diplopoda). Bull. Mus. natn. Hist. nat. Paris, $4^{\mathrm{e}}$ sér. 9 , sect. A 1, pp. 169-199.

Posada, D., Crandall, K.A., 1998. Modeltest: testing the model of DNA substitution. Bioinformatics 14, 817-818.

Regier, J.C., Shi, D., 2005. Increased yield of PCR product from degenerate primers with nondegenerate, nonhomologous $5^{\prime}$ tails. BioTechniques. In press. 
Regier, J.C., Shultz, J.W., 2001a. A phylogenetic analysis of Myriapoda (Arthropoda) using two nuclear protein-encoding genes. Zool. J. Linn. Soc. 132, 469-486.

Regier, J.C., Shultz, J.W., 2001b. Elongation factor-2: a useful gene for arthropod phylogenetics. Mol. Phylogen. Evol. 20, 136-148.

Regier, J.C., Paukstadt, U., Paukstadt, L., Mitter, C., Peigler, R.S., 2005. Phylogenetics of eggshell morphogenesis in Antheraea (Lepidoptera: Saturniidae): unique origin and repeated reduction of the aeropyle crown. Syst. Biol. In press.

Regier, J.C., Shultz, J.W., Kambic, R.E., 2004. Phylogeny of basal hexapod lineages and estimates of divergence times. Ann. Entomol. Soc. Am. 97, 411-419.

Schileyko, A.A., 1992. Scolopenders of Vietnam and some aspects of the system of Scolopendromorpha (Chilopoda, Epimorpha). Part 1. Arthropoda Selecta 1, 5-19.

Schileyko, AA., 1996. Some problems in the systematics of the order Scolopendromorpha (Chilopoda). Mem. Mus. Natn. Hist. Nat. 169, 293-297.

Schileyko, A.A., Pavlinov, I.Ja., 1997. A cladistic analysis of the order Scolopendromorpha (Chilopoda). Ent. Scand. Suppl. 51, 33-40.

Shelley, R.M., 2002. A synopsis of the North American centipedes of the order Scolopendromorpha (Chilopoda). Virginia Museum Nat. Hist. Mem. 5, 1-108.

Shultz, J.W., Regier, J.C., 2000. Phylogenetic analysis of two nuclear protein-encoding genes in arthropods supports a crustacean-hexapod clade. Proc. R. Soc. Lond. B 267, 1011-1019.

Sierwald, P., Shear, W.A., Shelley, R.M., Bond, J.E., 2003. Millipede phylogeny revisited in the light of the enigmatic order Siphoniulida. J. Zool. Syst. Evol. Res. 41, 87-99.

Smith, S.W., Overbeek, R., Woese, C.R., Gilbert, W., Gillevet, P.M., 1994. The genetic data environment and expandable GUI for multiple sequence analysis. Comput. Appl. Biosci. 10, 671-675.
Sorenson, M.D., 1999. TreeRot, version 2. Boston University, Boston, MA.

Staden, R., Beal, K.R., Bonfield, J.K., 1999. The Staden package, 1998. In: Misener, S., Krawetz, S. (Eds.), Bioinformatics Methods and Protocols. Humana Press, Totowa, NJ, pp. 115-130.

Strother, P.K., Al-Hajri, S., Traverse, A., 1996. New evidence from land plants from the lower Middle Ordovician of Saudi Arabia. Geology $24,55-58$.

Swofford, D.L., 1998. PAUP*, 4.0 vB10. Sinauer, Sunderland, MA.

Wellman, C.H., Gray, J., 2000. The microfossil record of early land plants. Phil. Trans. Roy. Soc. Lond. B 355, 717-732.

Wellman, C.H., Osterloff, P.L., Mohiuddin, U., 2003. Fragments of the earliest land plants. Nature 425, 282-285.

Wilson, H.M., 2005. Zosterogrammida, a new order of millipedes from the Middle Silurian of Scotland and the Upper Carboniferous of Euramerica. Palaeontology. In press.

Wilson, H.M., in review. Juliform millipedes from the Lower Devonian of Scotland and the Maritime Provinces, Canada: implications for the timing of millipede cladogenesis in the Paleozoic.

Wilson, H.M., Anderson, L.I., 2004. Morphology and taxonomy of Paleozoic millipedes (Diplopoda: Chilognatha: Archipolypoda) from Scotland. J. Paleont. 78, 169-184.

Wilson, H.M., Hannibal, J.T., 2005. Taxonomy and trunk-ring architecture of pleurojulid millipedes (Diplopoda: Chilognatha: Pleurojulida) from the Upper Carboniferous of Europe and North America. J. Paleortol. 79(6). In press.

Wilson, H.M., Shear, W.A., 2000. Microdecemplicida, a new order of minute arthropleurideans (Arthropoda: Myriapoda) from the Devonian of New York State, USA. Trans. Roy. Soc. Edinburgh: Earth Sci. 90, 351-375. 